\title{
Digital competences of parents in the matter of electronic threats
}

\author{
Eukasz Tomczyk ${ }^{1, *}$ \\ ${ }^{1}$ Pedagogical University of Cracow, Ingardena 4 street, 30-060 Kraków, Poland
}

\begin{abstract}
Digital competences have become one of basic skills in XXI century. Due to the ability to digitally access data and manage information and use electronic services, the quality of life has improved, and there has been an improvement in many activities connected with communication, shopping, ticket booking and a range of other repetitive activities. However, there is an additional layer overlapping the technical skills, which layer is connected with understanding the threats deriving from common availability of ICT. The aim of this paper is a diagnosis of digital competences level of parents in the matter of safe use of electronic media. To do this, quantitative research have been prepared, which measure six crucial areas of internet threats: ability to evaluate reliability of information on Internet, safety in the matter of contact with other users, image protection on Internet, knowledge concerning copyrights, knowledge concerning cyber-bullying mechanisms, proper performance of financial operations. The weakest areas of digital literacy seem to be: copyright protection and issues concerning contact with other users. The research was realized with the use of a competence test. The analysis was carried out on 260 parents of students attending secondary schools in the second half of 2016.
\end{abstract}

\section{Introduction}

Today's generation of young Internet users are mainly digital natives who do not know life without new technologies. For them, using mobiles, Internet, game consoles or digital television is as normal as using "old media" (radio, television) for their parents. Both generations are going through similar processes that are taking place in information society, have educational impact on one another and mutually model values, according to $\mathrm{M}$. Mead's concept. This happens also through and with the support new media.

Parents see that new technologies bring not only positive changes associated with quick access to information, data sharing or various forms of entertainment, but they also generate many threats, [11,13]. Ability to participate intentionally in new media space requires taking advantage of the positive aspects of digital media, and protection against both, popular and less visible e-threats, such as: cyberbullying, [3]. Internet addiction and various forms of pathologic use of it, [15], sexting [7], self-control and self-evaluation in terms of using electronic media [1], protection of online image [4] or legal consequences of Internet abuse, [21]. These threats are only typical and the most common, negative results of

*Corresponding author: tomczyk_lukasz@prokonto.pl 
omnipresence of electronic media. Once in a while, the group of typical and well known risky behaviours grows by new media-related situations that refer, for example, to promoting destructive behaviours like patostreaming or fake news.

With the growing number of online threats, it becomes necessary to develop new skills that would allow to improve digital safety in families. Individuals who do not properly understand how new media works and how to secure their electronic devices, are the most prone to different limit situations. Therefore, central government administration units, NGOs and schools more and more often take responsibility for raising the level of digital safety Following one's intuition, searching for support in Internet portals dedicated to solving educational issues, family counselling or consultations with other parents may prove to be insufficient in the age of increasing electronic threats, [2,20].

\section{Definition of digital literacy in the aspect of e-threats}

There is a reason why digital literacy, or wider, IT literacy, is considered one of the key skills, along with: literacy and languages; basic skills in maths, science and engineering; personal, social and learning competencies; civic competence; entrepreneurship, and cultural awareness and expression. This set has been agreed by the European Parliament and European Commission as a set of necessary, basic competencies that enable full family and professional functioning, [5]. Digital literacy (DL) is an ability to use of new media fluently, usually in the technical context of obtaining, processing, presenting, sending and archiving data, by means of applications and websites However, it is worth to add that DL is also an ability to understand changes caused by new media. Thus, it is the ability to interpret processes associated with positive and negative influence on children, self, family and society, [6]. Holistic view of DL involves connecting knowledge and technical skills with reflection on the influence of electronic media on individuals and groups.

DL are also connected with ability to create, and securing access to the Internet, digital etiquette and digital safety, [19,14]. Development of Internet-based technologies also forces parents to know not only typical digital threats, but also those hidden in other networked devices, for example toys that collect and process data about activity in family environment or spyware, [7]. We need to point out that without adequate and proven educational methods, having advanced DL is insufficient to strengthen digital safety, [12]. Therefore, the subject matter literature mentions a subcategory of digital literacy, described as "family digital literacy" [10], meaning DL extended by skills regarding education to safe use of digital media and also ability of parents to self-educate [17] and extend media socialisation onto other family members [18], including older generations who have been increasingly better in using digital media [9].

Save for traditional offline threats, modern parents are forced to develop their awareness and educational strategies related to online reality. Offline and online threats are very often intertwined, and effective minimising means development of knowledge and skills that are useful in both of these environments, creating a set of factors protecting from risky behaviours.

\section{Methodology}

\subsection{Research objectives}

The objective of the study was to diagnose level of digital literacy of parents, in the area of secure use of new media. This is to improve cognition and application, by diagnosing the weakest DL components and strengthening them through engaging parents in informal 
education process. The research was commissioned by the Polish Ministry of National Education and conducted by Cities on the Internet Association from Tarnow, within the program Bezpieczna+ (Safety+). Data was collected during realisation of the project Cyfrowo Bepieczni (Digitally Safe).

\subsection{Sampling and research procedure}

Schools that participated in the Digitally Safe project were responsible for diagnosing DL level of their students, parents and teachers. This text presents results of a competency test, in six priority DL areas, such as: protection of image in the Internet, sexting and data privacy, copyright, credibility of information, cyberbullying and financial operations. For each area 3 indicators were designed and obtained based on answers to questions checking knowledge and skills. The whole test consisted of 18 questions rated with points (positive points for every correct answer, for partially correct answers, e.g. selection of only some correct answers - some positive points, and negative points for wrong answers). Then, the total number of points for each area was calculated and finally, a percentage result $(100 \%$ meant correct answers to all the questions) was drawn.

The research was anonymous and conducted according to pedagogical research ethics. Data was collected by a private research-educational agency NAVIGO, led by dr Łukasz Srokowski. The tool and methodology were consulted with dr Arkadiusz Wąsiński from the University of Lodz.

\subsection{Sample characteristics}

The survey was conducted among parents of students learning in secondary schools in Poland, in the second half of 2016. The sample consisted of 183 women (70.66\%) and 76 men $(29.34 \%)$. Education of parents was: vocational (15.83\%), secondary $(41.70 \%)$, higher $(30.89 \%)$, post-secondary $(5.79 \%)$, lower-secondary $(2.32 \%)$, primary $(3.47 \%)$. Respondents stated their families lived modestly $(11.97 \%)$, had financial means adequate to their needs $(65.25 \%)$, were well-off $(22.78 \%)$. The graph below presents how did parents evaluate their knowledge and skills related to electronic threats.

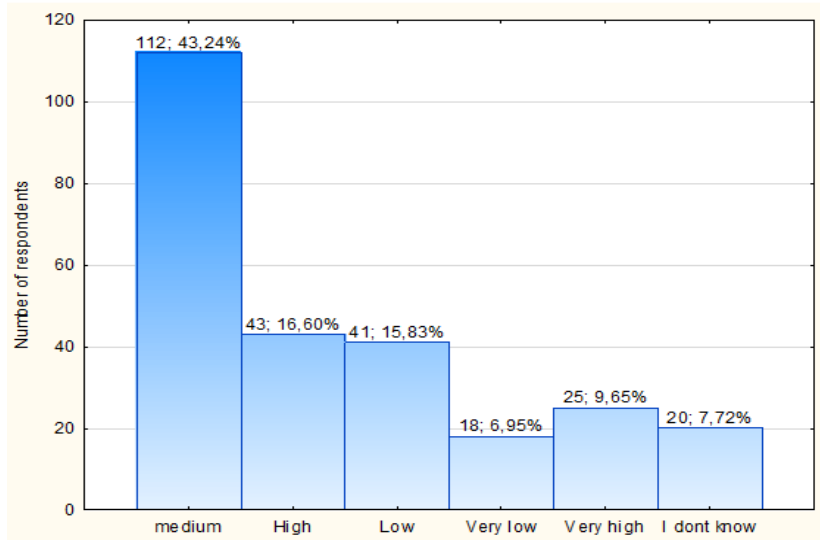

Figure 1. How do you evaluate your level of literacy and knowledge related to securing against ethreats?

\section{Results}


Parents obtain relatively satisfactory results as for protection of online image and cyberbullying prevention. These two areas are also strongly related. Unsatisfactory results refer mainly to copyright, that is information about downloading and sharing copyrighted files in the Internet, and safe interactions with other Internet users (including sexting).

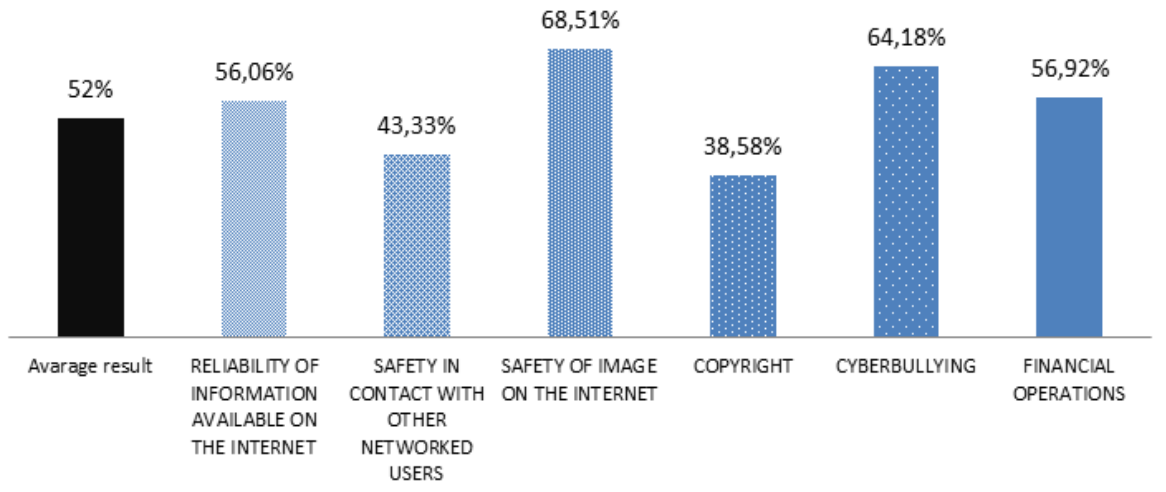

Figure 2. Average results in competency test, Source: (Tomczyk, Srokowski, Wąsiński, 2016).

Presented percentage distribution of correct answers indicates a necessity to improve DL in the analysed group, as level of knowledge and skills of parents determines digital safety in the family.

Parents who regularly use e-services like e-administration, had much better test results than the rest of the group $\mathrm{F}(3,255)=4.4631, \mathrm{p}=.00448$. In schools where a serious incident of breaching digital safety had taken place, parents obtain slightly better results $\mathrm{F}(2$, $256)=6.2733, \mathrm{p}=.00219$. Regardless if there are special, comprehensive programs introduced in a school or if there are no DL development procedures in terms of digital safety, parents obtain similar results $\mathrm{F}(2,256)=2.0752, \mathrm{p}=.12764$. Thus, we can develop a working hypothesis that it is more individual conditions that facilitate parents' knowledge and competencies rather than school programs within the so called non-formal education. Controlling the ways the youngest family members use new technologies is not related to test results $\mathrm{F}(4,254)=1.6990, \mathrm{p}=.15069$. Similarly, there are no correlations for talking with children about electronic threats $\mathrm{F}(5,253)=1.4823$, $\mathrm{p}=.19602$. At the same time, we should point out that parents who highly evaluate their literacy and knowledge about e-threats, obtained high results in the competency test $F(5,253)=7.1716, p=.00000$. Parents who think their competencies in using digital devices like computer and Internet are high or very high, get good or very good results. It means parents evaluate themselves adequately. This refers also to parents who stated their DL are at a low level $\mathrm{F}(5,253)=6.5660, \mathrm{p}=.00001$.

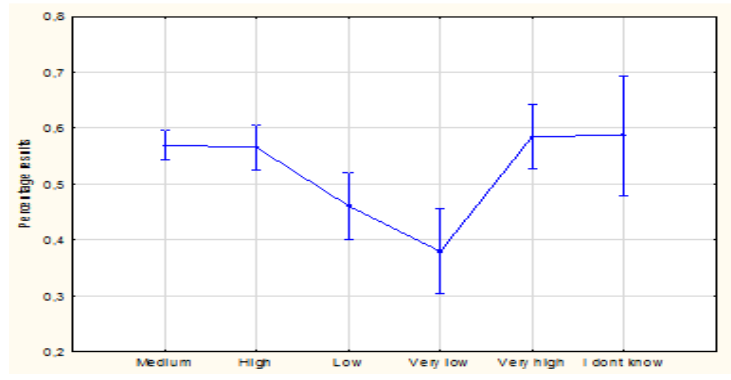

Figure 3. How do you evaluate your level of literacy and knowledge related to use of digital devices (computer, Internet)? 
Similar strong relation can be found for results regarding self-evaluation of ability to use portable devices like tablet or smartphone $\mathrm{F}(5,253)=5.7995, \mathrm{p}=.00004$. Place of residence does not affect the discussed DL aspect in any way $F(4,254)=1.2786, p=.27885$. DL is not influenced by gender $\mathrm{F}(1,257)=4.6867, \mathrm{p}=.03132$ (very small statistical difference between test results), education $\mathrm{F}(5,253)=1.9192, \mathrm{p}=.09159$, or declared financial standing $\mathrm{F}(2,256)=1.2168, \mathrm{p}=.29789$.

For each DL component, an average value was calculated based on points received in the test. Each variable (DL component) turned into arithmetic value out of three answers, was compared to other variables using Pearson correlation coefficient. We can notice that all results have high level of confidence $-\mathrm{p}$ is less than 0.001 . A general conclusion is that advanced knowledge and skills in one area of DL translates into w high or average level in other DL areas. This correlation is the strongest for the area of financial operations. This may result from the fact that technical knowledge regarding access to one's account, ability to recognise different types of attacks on bank accounts or other confidential data needed for processing financial information, requires parents to be aware of other areas, like evaluating credibility of information or mechanisms that strengthen online privacy. Linear correlation is visible, but we should point out that there are many mediating factors to DL.

Table 1. Relation between certain DL components in the area of security

\begin{tabular}{|c|c|c|c|c|c|}
\hline & Image on Internet & Sexting and privacy & Intellectual law & Information trust & Cyberbullying \\
\hline Sexting and privacy &, $2689 * * *$ & 1,0000 & & & \\
\hline Intellectual law &, $1779 * *$ &, $3008 * * *$ & 1,0000 & & \\
\hline Information trust &, $2808 * * *$ &, $3439 * * *$ &, $3750 * * *$ & 1,0000 &, $4030 * * *$ \\
\hline Cyberbullying &, $2394 * * *$ &, $3250 * * *$ &, $2888^{* * *}$ & 1,0000 \\
\hline Financial operations &, $2607 * * *$ &, $3409 * * *$ &, $3821 * * *$ &, $4393 * * *$ &, $4470 * * *$ \\
\hline
\end{tabular}

${ }^{*} \mathrm{p}<0.01 ; * * \mathrm{p}<0.05, * * * \mathrm{p}<0.001$

\section{Discussion}

Considering diagnostic of digital literacy, we should emphasize that proposed methodology, basing on six selected competencies in the area of digital safety, does not exhaust the scope of factors assigned to different variables. Due to volume limitations of competency tests, our methodology was designed to measure safety issues related to the most popular networked services, accompanying skills and knowledge. Authors of the tool are aware that changing reality of the information society generates many new problems, thus factors and variables that define digital safety are fluent and transform over time.

It is worth to point out that many of the six selected DL components intertwine. This is confirmed, for example, by $\mathrm{r} 2$ test coefficients, as well as percentage distribution of answers to questions about cyberbullying and protection of online image. We also need to emphasize that cyberbullying and relatively advanced knowledge parents have about online image are connected with years of prevention of risky behaviours in this area, carried out by NGOs like Empowering Children Foundation or activities of Ministry of Education, Educational Supervising Authorities and Police. These initiatives are strengthened with media messages about causes and consequences of long-term or serious cyberbullying, for 
example sexual abuse. Some forms of cyberbullying are not just" excesses" of adolescence, but they can be classified as stalking or infringement of personality rights. Probably, because these preventive activities have been carried out a long time, the respondents obtained high results in the area of cyberbullying.

Dynamics of changes happening in the information society forces us to modify our view on DL. Therefore, we postulate that future competency tests addressed to parents, teachers and students should include the following issues: fake news, problematic use of Internet (including FOMO and Internet addiction) or patostreaming. They are phenomena that also require an in-depth analysis.

\section{Conclusion}

DL is definitely one of the key competencies in today's world. When DL is analysed in the context of family functioning, they receive a completely new meaning. There are many DL factors related to: technical use of media, reflection regarding influence, preventive skills or response to electronic threats. Usually, parents update their DL through self-education. This may not be apparent, but DL is a complex hybrid of knowledge, skills and attitudes connected with new media, that transform along with the development of digital services. The research results presented in this test indicate that some DL components are significantly related with one another.

Awareness of the necessity to develop DL in Poland grows, also in the context of lifelong learning. This is proved, among others, by ministerial projects dedicated to the development of DL not only among students and teachers, but also parents. At the same time, parents responsible for digital safety, begin to recognise the necessity of improving their own knowledge in a non-formal or informal way. We also need to point out that the research results show a relatively high level of self-awareness regarding DL. Unfortunately, despite the above mentioned positive conditions, the results in the selected areas of the competency test should be treated as an argument to design further systemic and one-time solutions facilitating development of DL.

\section{Acknowledge}

Research was realized in the frame of CyfrowoBezpiecznie project, realized by Stowarzyszenie Miasta w Internecie (Tarnów) in the frame of Bezpieczna+ ministry programme. The author would like to thank the research team eg. dr. Łukasz Srokowski (NAVIGO), for administrative part of this project.

\section{References}

1. Bayraktar, F. Online Risks and Parental Mediation Strategies Comparison of Turkish Children/Adolescents Who Live In Turkey and Europe. TED EĞİTiM VE BİLİM. doi:10.15390/eb.2017.6323, (2017).

2. Davis, V. Interconnected But Underprotected? Parents' Methods and Motivations for Information Seeking on Digital Safety Issues. Cyberpsychology, Behavior \& Social Networking, 15(12), 669-674. doi:10.1089/cyber.2012.0179, (2012).

3. Del Rey, R., Casas, J. A., Ortega-Ruiz, R., Schultze-Krumbholz, A., Scheithauer, H., Smith, P., ... Plichta, P. Structural validation and cross-cultural robustness of the European Cyberbullying Intervention Project Questionnaire. Computers in Human Behavior, 50, 141-147. doi:10.1016/j.chb.2015.03.065, (2015). 
4. Frania, M. Selected aspects of media literacy and new technologies in education as a challenge of Polish reality. Perspectives of Innovations, Economics and Business, 14(2), 109-112. doi:10.15208/pieb.2014.13, (2014).

5. García-Lozano, C., Las-Heras-Casas, J., Fraile-García, E., \& Ferreiro-Cabello, J. DIDACTIC STRATEGIES TO DEVELOP KEY COMPETENCIES. INTED2016 Proceedings. doi:10.21125/inted.2016.0958, (2016).

6. Hannaford, J., \& Beavis, C. When will the Internet be connected? Digital worlds and belonging in the lives of globally mobile children. Literacy, 52(1), 47-54. doi:10.1111/lit.12123, (2018).

7. Harrison, E., \& McTavish, M. 'i'Babies: Infants' and toddlers' emergent language and literacy in a digital culture of iDevices. Journal Of Early Childhood Literacy, 18(2), 163-188. doi:10.1177/1468798416653175, (2018).

8. Kopecký, K. Sexting Among Slovak Pubescents and Adolescent Children. Procedia Social and Behavioral Sciences, 203, 244-250. doi:10.1016/j.sbspro.2015.08.289, (2015).

9. Mackowicz, J., \& Wnek-Gozdek, J. "It's never too late to learn"-How does the Polish U3A change the quality of life for seniors? Educational Gerontology, 42(3), 186-197. doi:10.1080/03601277.2015.1085789, (2015).

10. Marsh, J., Hannon, P., Lewis, M., \& Ritchie, L. Young Children's Initiation into Family Literacy Practices in the Digital Age. Journal Of Early Childhood Research, 15(1), 47-60, (2017).

11. Plichta, P., \& Pyżalski, J. Narażenie uczniów ze specjalnymi potrzebami edukacyjnymi na hazard tradycyjny $i$ internetowy oraz inne zachowania ryzykowne. Niepełnosprawność. doi:10.4467/25439561.np.16.015.6841, (2016).

12. Rodríguez-de-Dios, I., van Oosten, J. M., \& Igartua, J. A study of the relationship between parental mediation and adolescents' digital skills, online risks and online opportunities. Computers In Human Behavior, 82186-198. doi:10.1016/j.chb.2018.01.012, (2018).

13. Siegle, D. Cyberbullying and Sexting: Technology Abuses of the 21 st Century. Gifted Child Today, 33(2), 14-16, (2010).

14. Szotkowski, R. Dangerous behavior of children and youth in the internet and possibility of their protection. Journal of Technology and Information, 2(1), 110-114. doi:10.5507/jtie.2010.024, (2010).

15. Tomczyk, Ł., \& Selmanagic-Lizde, E. Fear of Missing Out (FOMO) among youth in Bosnia and Herzegovina - Scale and selected mechanisms. Children and Youth Services Review, 88, 541-549. doi:10.1016/j.childyouth.2018.03.048, (2018).

16. Tomczyk, Ł., Srokowski, Ł., Wąsiński, A. Kompetencje w zakresie bezpieczeństwa cyfrowego w polskiej szkole. Tarnów: Stowarzyszenie Miasta w Internecie, (2016).

17. Veteska, J. Uvod do teorie zdelavani dospelych a andragogiky. Usti nad Labeb: Univerzita J. Purkyne, (2017).

18. Walotek-Ściańska, K. Persuasion strategies in Polish advertisements addressed to young people. Zeszyty Naukowe Wyższej Szkoły Humanitas Zarządzanie, 18(1), 0-0. doi:10.5604/01.3001.0010.2886, (2017).

19. Wang, X., \& Xing, W. Exploring the Influence of Parental Involvement and Socioeconomic Status on Teen Digital Citizenship: A Path Modeling Approach. Educational Technology \& Society, 21(1), 186-199, (2018). 
20. Wurtele, S. K., \& Kenny, M. C. Technology-Related Sexual Solicitation of Adolescents: A Review of Prevention Efforts. Child Abuse Review, 25(5), 332-344. doi:10.1002/car.2445, (2016).

21. Ziemba, E. Factors Affecting the Adoption and Usage of ICTs within Polish Households. Proceedings of the 2016 InSITE Conference. doi:10.28945/3508, (2016). 